\title{
The Outlook for Residential Electricity Prices in Australia's National Electricity Market in 2020
}

\author{
Paul Simshauser and Tim Nelson * \\ Level 6, 144 Edward Street \\ Brisbane, QLD 4001. \\ January 2013
}

\begin{abstract}
Australian electricity tariffs have increased by more than 10\% (year-on-year) since 2009 while inflation has remained below 3\%. This can be contrasted with the previous 18 years where electricity prices decreased in real terms. Policymakers are rightly focused on significant demand-side reforms and our analysis reveals this could result in electricity prices falling by $10 \%$ by 2020 in real terms.
\end{abstract}

\section{Introduction}

Australia has about 9 million residential and 1.2 million business electricity consumers. Households depend upon competitively priced electricity for the essentials in life and businesses cannot produce goods and services without it. Historically, electricity purchase decisions by Australian households and firms required little thought. Although there was an initial wave of over-investment from the late-1970s to the mid-1980s, it was followed by sustained microeconomic reforms of the supply-side of the electricity industry. A 2002 Energy Market Review by Parer (2002) found that those supply-side reforms of the Australian electricity industry delivered GDP benefits of $\$ 2$ billion annually. Above all, electricity prices fell in real terms throughout the period spanning 1985 to 2007.

However since 2008, there have been marked increases in the price of electricity. This is shown in Figure 1, which depicts the year-on-year change in the Consumer Price Index (CPI) and the Electricity Price Index from 1985 to December 2012. The most striking observation from Figure 1 is the diversion between general price inflation and electricity price inflation from 2008. Default electricity tariffs have increased by more than $10 \%$ (year-on-year) since 2009 while general inflation has remained below 3\%. This can be contrasted with the previous 18 years where electricity prices decreased in real terms. With such a significant structural break, policy makers have rightly begun to focus on significant demand-side reforms aimed at reducing electricity prices. Our subsequent analysis in this article reveals that these reforms could result in electricity prices falling by $10 \%$ by 2020 in real terms.

\footnotetext{
* Paul Simshauser is the Chief Economist at AGL Energy Ltd and Professor of Economics at Griffith University. Tim Nelson is the Head of Economics, Policy \& Sustainability at AGL Energy Ltd and an Adjunct Researcher at the University of New England. An earlier version of this article formed part of the Committee for Economic Development of Australia's 2013 Economic \& Political Overview. The views contained in this article are those of the authors and not necessarily those of AGL Energy Ltd.
} 
Figure 1: $\quad$ Consumer Price Index and Electricity Price Index (YoY Change)

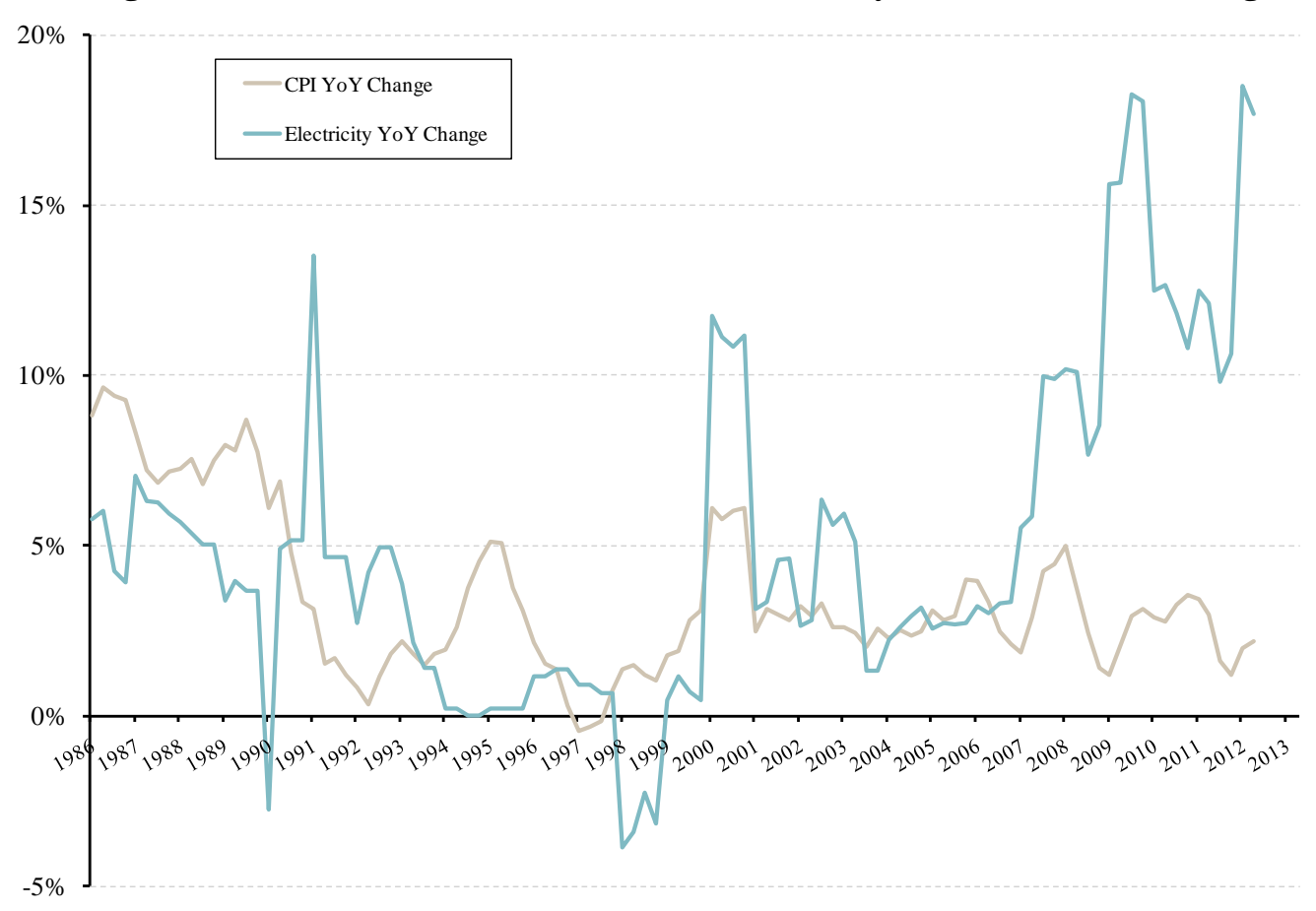

Source: ABS (Category 6401.0)

Australia's largest 250 business users consume 40 percent of national electricity output. At the same time that electricity prices have been rising, many businesses have been adversely affected by rising business costs and the rising Australian dollar. With Australia's terms of trade retreating from record highs, improving national productivity has rightly become a focal point, and as the Australian Government's independent economic agency (i.e. the Productivity Commission) recently noted, the electricity industry has an important role to play given the recent run-up in the capital stock (Banks, 2012).

This article is structured as follows: first, we provide a history of the Australian electricity market and pricing to 2008 to give context to the current debate. Second, we examine why electricity prices have increased markedly since 2008 . Third, we discuss current pricing trends and what electricity prices in 2020 may look like. Finally, we provide recommendations for policy reform intended to alleviate electricity pricing pressures.

\section{A brief history of electricity prices in Australia to 2008}

The electricity industry is generally characterised as having three supply chain components: generation (i.e. power stations), transmission and distribution (i.e. poles and wires) and retail supply (marketing, customer services and billing). Generation operates through competitive markets, including the National Electricity Market (NEM) on the east coast, and the South-West Interconnected System on the west coast, while the natural monopoly components (transmission and distribution) are price-regulated by the Australian Energy Regulator. Retail prices are generally competitive, but price regulation remains a policy constraint in New South Wales, Queensland and Western Australia, and regulatory outcomes therefore play a key role in determining the efficiency, competitiveness and innovation of retail electricity supply in Australia. Victoria and South Australia have deregulated their retail electricity markets, allowing consumers greater choice thereby facilitating investment and innovation. 
Figure 2: $\quad$ Electricity prices in Australia to 2008

Average Residential Tariff

(Nominal \$/MWh)

Average Residential Tariff (Real 2008 \$/MWh)

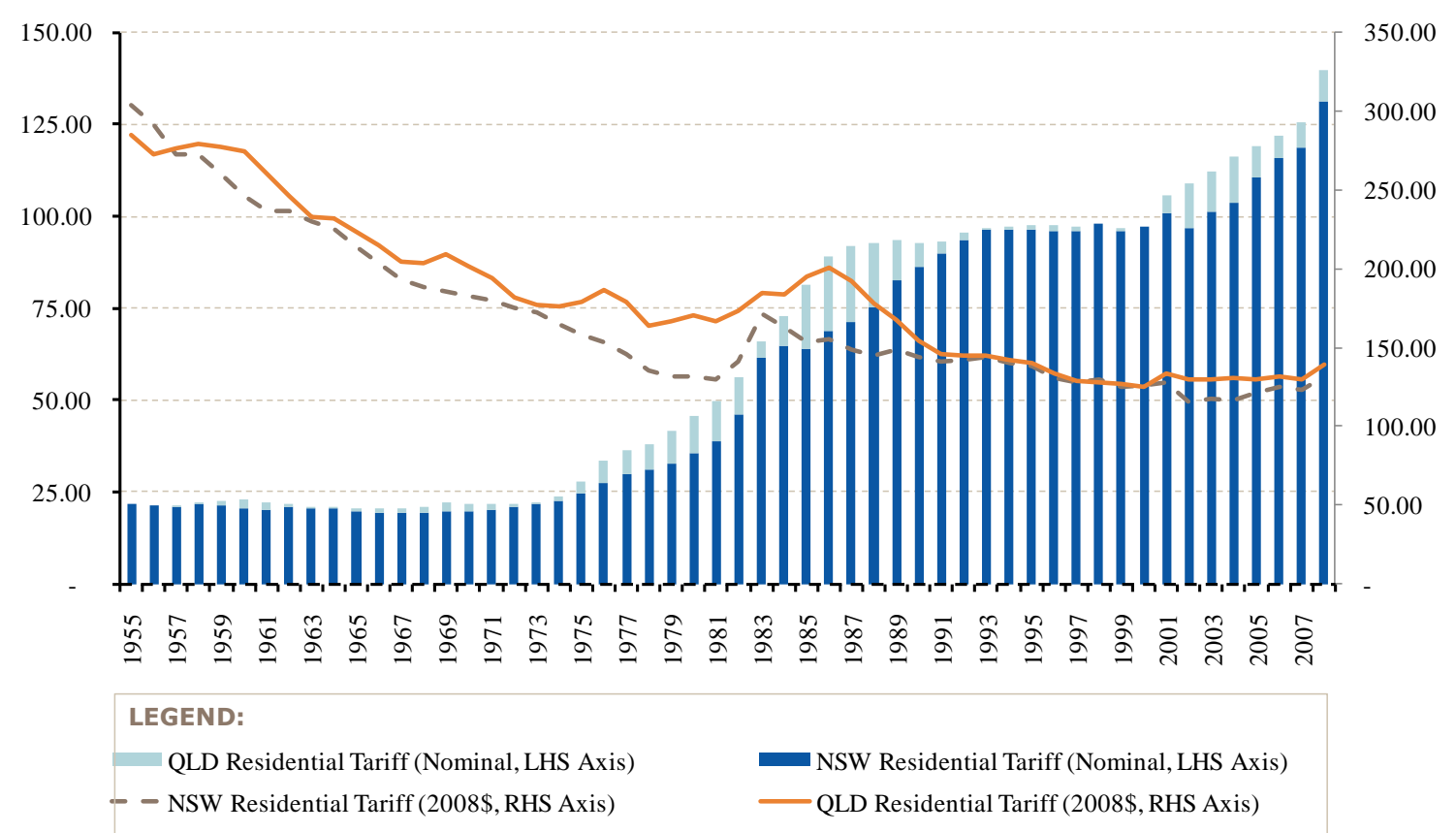

Source: Simshauser, Nelson and Doan (2011)

Figure 2 shows real electricity prices (line series) and nominal electricity prices (bar series) for New South Wales and Queensland residential customers from 1955-2008. Two periods of sustained real price reductions are discernable: (1) the period between 1955 and 1979; and (2) the period between 1985 and 2008. The period between 1955 and 1979 was characterised by significant expansion within the industry. Larger coal-fired power stations were constructed and economies of scale resulted in real reductions in the cost of energy supply. Installed generation capacity in Australia increased from 3500 MW in 1955 to 24,000 MW by the late-1970s. Over the same time period, households in New South Wales and Queensland increased their consumption from $2 \mathrm{MWh}$ per annum to $6 \mathrm{MWh}$ per annum. By 1979, the real price of electricity had fallen by a third from around \$300/MWh to about \$150/MWh.

However, it is the second period of real price reductions between 1985 and 2008 which is of more interest to our analysis. The early 1980's saw rapid price increases over a short period of time. This was the result of significant investments in power infrastructure to overcome shortages of supply, but quickly turned into an 'over-equipment scenario'. As a consequence of these price increases and a general desire to improve the productivity of the Australian economy, policymakers turned their attention to the management of the supply system, and later began a process of disaggregation, greater interconnection between regions, the introduction of competition, and privatisation. Vertically-integrated, state-owned monopoly electricity commissions were exchanged for competitive wholesale and retail trading markets, although the natural monopoly elements of the supply chain (i.e. the poles \& wires) remained price-regulated.

As a consequence of these largely supply-side reforms, real residential electricity prices (in 2008 dollars) fell from $\$ 220 / \mathrm{MWh}$ in 1985 to $\$ 150 / \mathrm{MWh}$ in 2008. In the regions which now form the NEM, total installed generation capacity over the period increased from 28,000 MW to 40,000 MW but most importantly, generation capacity utilisation improved considerably - from just $39 \%$ in 1985 to $58 \%$ in 2008 as Figure 3 notes. 
Figure 3: $\quad$ Generation capacity utilisation in the NEM region (1955-2008)

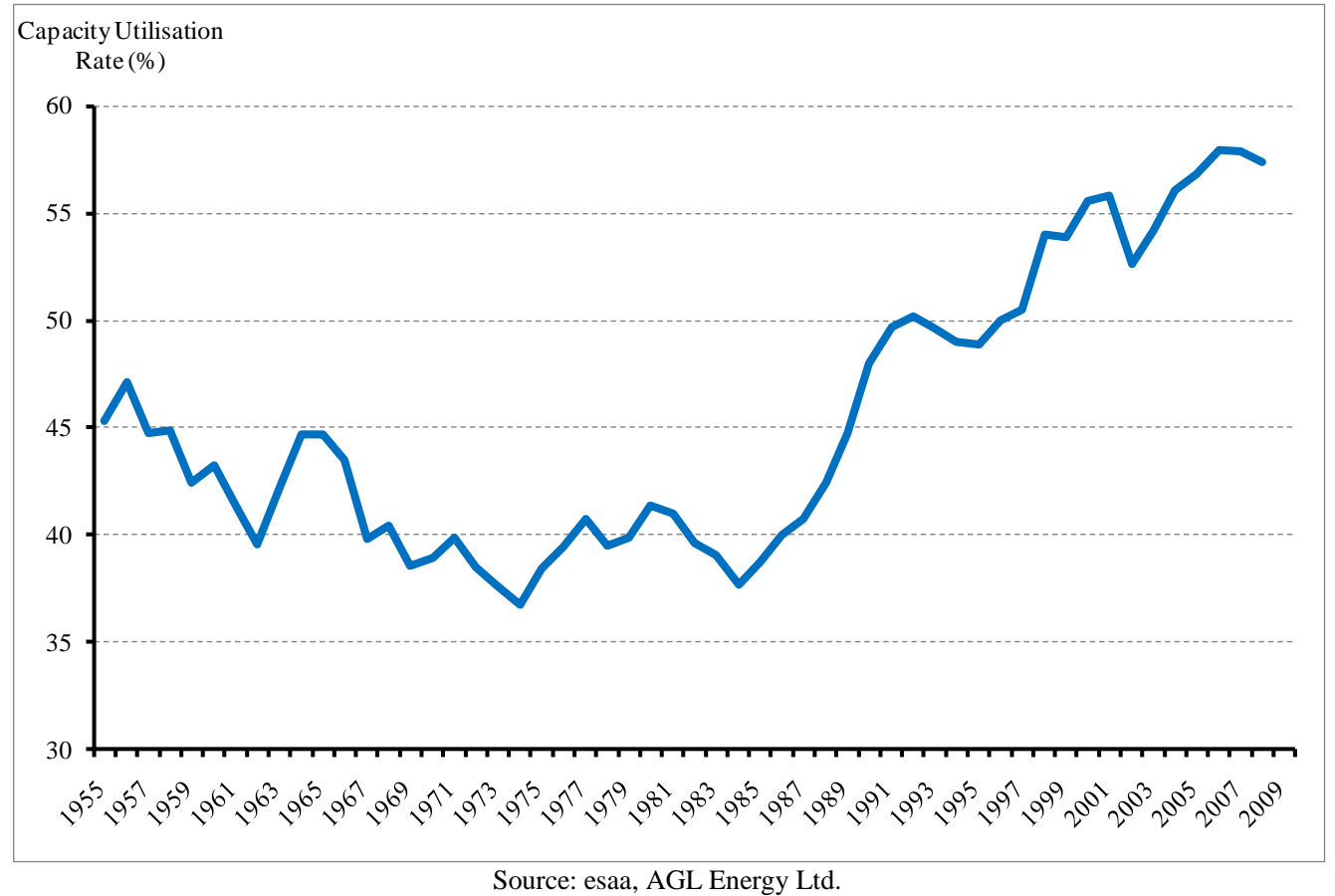

Figure highlights that plant capacity utilisation in the NEM regions in 1955 was $45 \%$. The productivity of the generation fleet deteriorated through to the mid-1980s before rebounding sharply through to 2008. The rise in plant performance, strengthened transmission interconnections, increased mining and industrial loads, ongoing improvements in investment decision making, greater use of flexible plant and the opening up of wholesale electricity markets to competition lifted sectoral efficiency and productivity. And so by 2008, plant utilisation rates had risen to $58 \%$. To be sure, there are limitations to system utilisation improvements - the 'binding constraint' relates to power system load factors and the requirement for 'reserve plant' to ensure security of supplies.

Since 2004, 'peak demand', that is, the highest level of demand in a year, increased at twice the rate of underlying energy demand, that is, the volume of energy sold in a year. This divergence in growth will lower the overall power system capacity utilisation rate (as Figure 8 later reveals), and underlies one of the primary reasons for electricity price rises between 2008 and 2013. Supply-side reforms achieved substantial improvements in power system utilisation rates, whilst simultaneously, consumers continued to use energy in a way which reduced capacity utilisation because market signals which would otherwise assist capital productivity (i.e. time-of-use tariffs) did not exist.

Peak demand (and more importantly, localised peaks at the distribution network element level) represent a largely unaddressed component of recent reforms. With the exception of Victoria from 2008 and South Australia from 2013, retail electricity prices for small business and residential consumers remain regulated, and even within Victoria, time-of-use pricing does not feature prominently due to a (transient) moratorium on such products following a particularly unpopular (and costly) mandated smart meter roll-out.

Historically speaking, we consider this to have been a critical oversight in policymaking with the notable exception of the AEMC. ${ }^{1}$ Electricity is relatively unique among goods and services because it cannot be stored economically. As it is produced, it must be consumed, and more importantly, vice versa - including suitable reserve plant margins (i.e. purposefully engineered excess capacity to ensure real-time supply meets the stated 'reliability criteria'). This remains a 
critical constraint - inventory management cannot be used to smooth production schedules, nor to meet variable demand, at least until energy storage becomes economic. Electricity markets are also characterised by significant demand variability as a result of changes in weather and anthropogenic patterns. Space heating and cooling results in rapid increases in the demand for electricity for short periods, principally on the hottest and coldest days of the year. One industry estimate has put the investment cost to serve critical peak demand at $\$ 8$ billion merely to serve 12 extreme weather days per annum. The Productivity Commission (2012) recently found that ' 25 per cent of retail electricity bills are required to meet around 40 hours of critical peak demand each year'. The presence of this investment raises the cost of electricity and places a visible drag on electricity industry performance, and therefore the productivity of the nation.

Genuine demand-side reform has not, thus far, been pursued with any real vigour. Retail electricity pricing is based on simple flat tariff structures. Applying this type of pricing framework to other industries would lead to material losses in welfare and economic efficiency as US energy economist Ahmad Faruqui (2010) once observed, imagine reverting to flat pricing in aviation - business travellers would be unable to secure seats during peak periods, and holiday travellers would no longer be able to find cheap fares. Aviation fleet utilisation would deteriorate rapidly and the average cost of flights would hence rise. Yet this is exactly how the energy sector prices its product. Time-of-use pricing is virtually non-existent at the domestic level with the exception of electric hot water loads. ${ }^{2}$

\section{Why have prices increased so significantly since 2008 ?}

In 2009, we produced a particular line of research on electricity prices that would eventually be published as The Boomerang Paradox articles in The Electricity Journal (Simshauser, Nelson and Doan, 2011a, 2011b). Starting from a residential tariff of approximately $\$ 150 / \mathrm{MWh}$ in 2008, we forecast that electricity prices would double by 2015 due to a range of factors. A breakdown of our original analysis is presented in Figure 4. The 2008 NSW residential tariff is presented on the left with each bar to the right representing the incremental increase associated with a range of cost drivers.

Figure 4: $\quad$ Boomerang Forecast Increase in Electricity Prices from 2008 to 2015

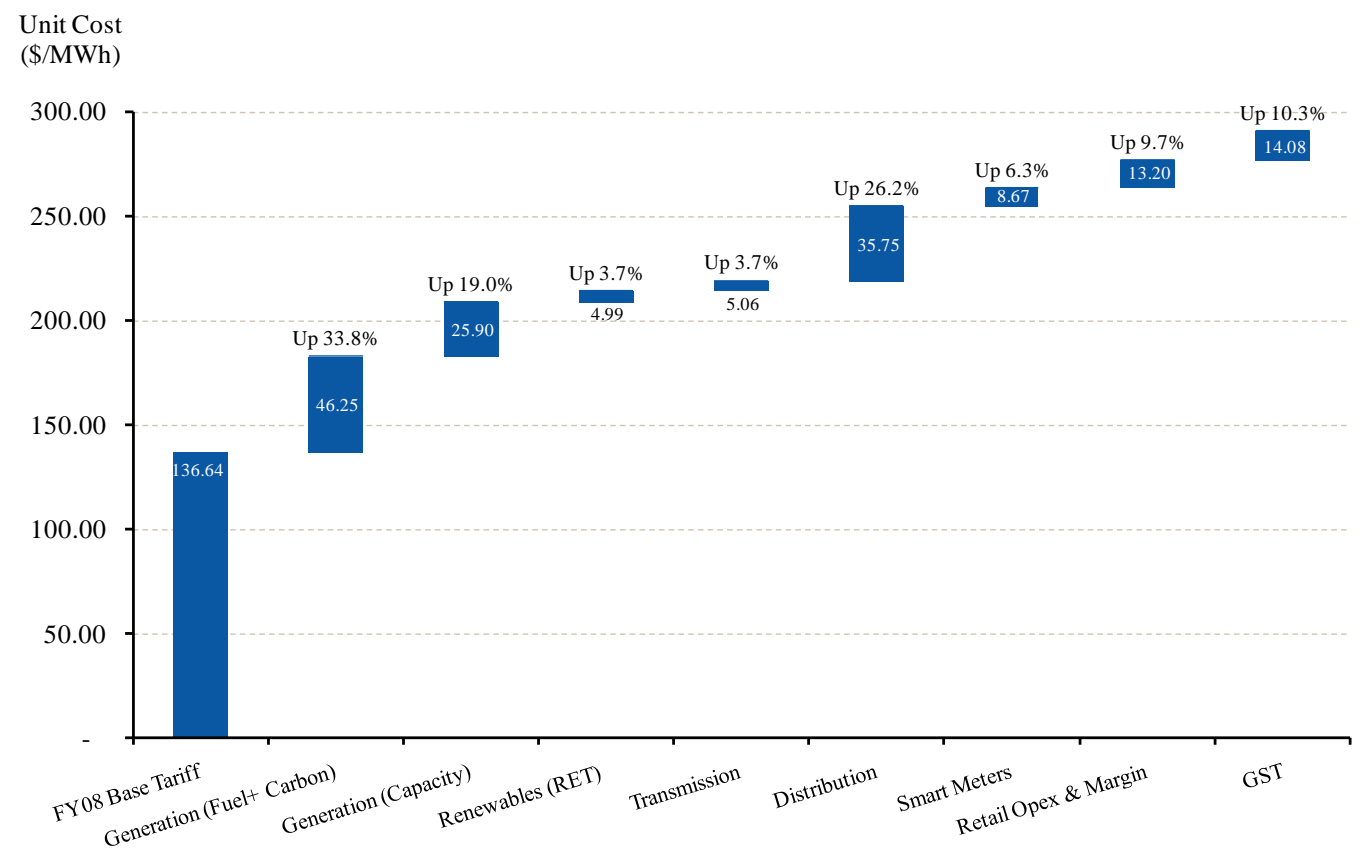

Source: Simshauser, Nelson and Doan (2011a) 
The price forecast was based around three drivers of higher costs: significant increases in network costs driven by higher capital expenditure and increasing peak demand; increases in wholesale energy costs driven by both higher costs of generation plant (arising from higher capital costs) and the cost of funds (cost of capital) and deteriorating utilisation rates as Figure 8 later reveals; and significant increases in the price of coal and gas due to rising international commodity prices. Some industry analysts point to lower wholesale energy prices in the NEM as evidence that wholesale energy costs have not increased. However, it is long-run costs, not short run wholesale prices that are relevant as Section 3.2 later explains. The sustainability of pricing outcomes in the NEM is an issue that the industry will need to turn its attention to over the coming years with the proliferation of very low short-run marginal cost plant such as wind farms, which were not anticipated when the NEM was originally designed in the 1990s.

The Australian Energy Market Commission (AEMC, 2011) also provided a pricing forecast for the period 2010/11 to 2013/14 which produced similar results (see Appendix I). Our forecasts, and those of the AEMC, were similar with much of the price increases associated with higher wholesale energy costs and significant increases in the cost of building and maintaining electricity networks. Unfortunately for energy consumers, these forecasts have proved to be more accurate than less. The 2012/13 New South Wales regulated residential tariffs are presented in Figure 5, and note that much of the price increases envisaged to 2015 have already occurred. Ausgrid serves the Sydney area, Endeavour serves western Sydney and Essential Energy serves rural New South Wales.

Figure 5: $\quad$ 2012/13 NSW Regulated Residential Tariff (by distribution network)

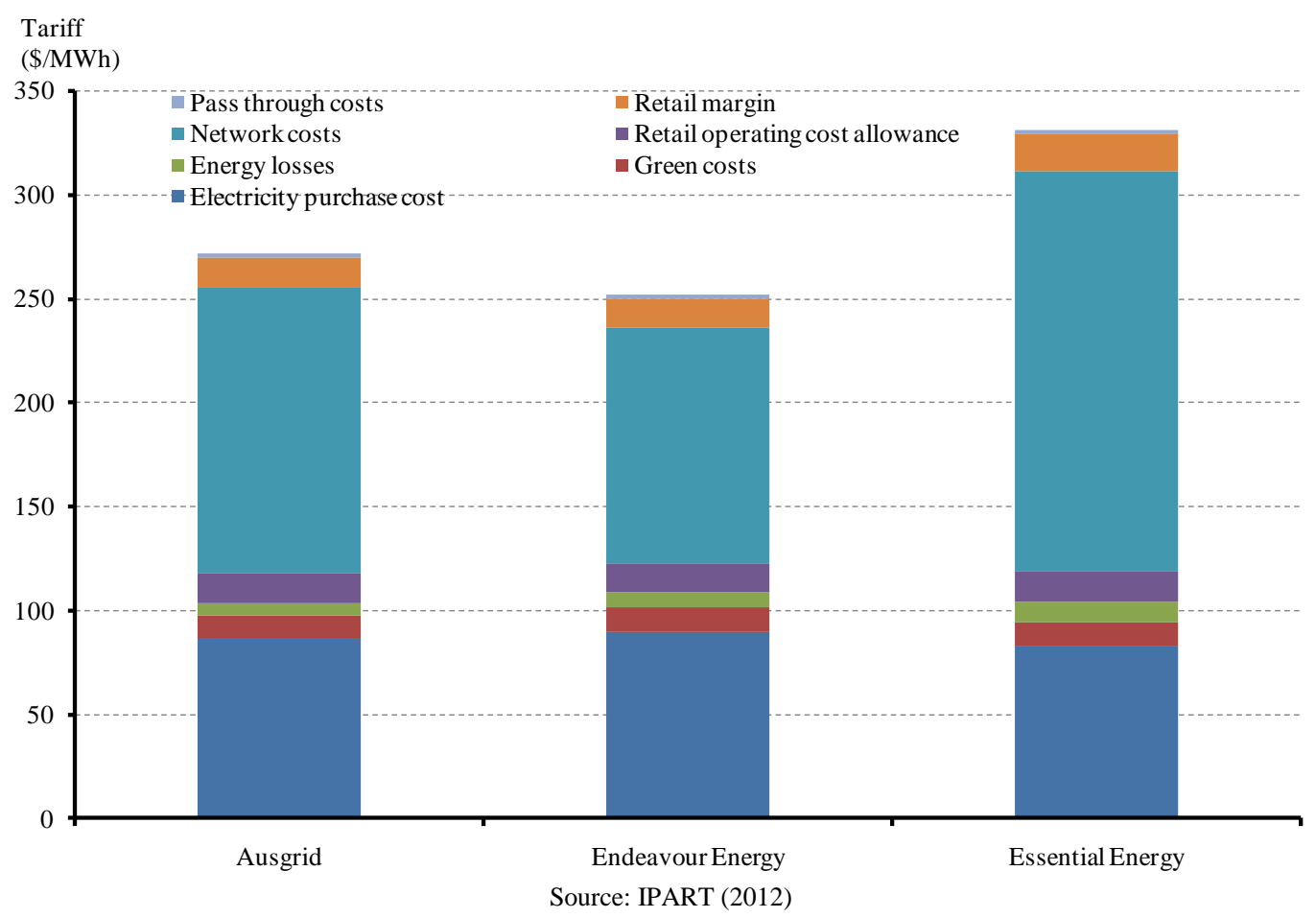

The critical question for policymakers is how best to repeat the 'harvest period' of 1985-2008 now that investments have been sunk? The short answer is to focus on demand-side reform. To understand this in more detail, we analyse the underlying cost drivers, namely: networks and the investment megacycle, wholesale energy cost drivers (including carbon pricing) and the impact of green energy policies. 


\subsection{Networks}

There has been a large increase in capital expenditure on electricity networks over the past five years. For example, between 2001-2005, aggregate capital expenditure on electricity networks in New South Wales and Queensland totalled just \$7 billion. In the period between 2010-2014, capital expenditure was expected to reach almost $\$ 30$ billion (Simshauser, Nelson and Doan, 2011). Much has been written on whether the capital invested and the subsequent price increases are justified. We do not offer a definitive explanation here, but a material component was driven by two factors (1) network augmentation to meet forecast rising peak demand at the network element level, and (2) replacement of aged assets. The AEMC (2011, p.2) concurred with this assessment stating that higher network tariffs are largely due to "peak demand, higher commodity prices, replacing aging assets and higher costs of capital due to the global financial crisis". Reliability standards in some jurisdictions were tightened, we would argue excessively and have almost certainly led to excess investment, but fortunately those standards have since become the subject of reform, as have other aspects of network regulation.

As outlined previously, peak demand growth in the Australian electricity industry has (until recently) outstripped growth in underlying energy demand. Figure 6 shows how the maximum summer demand in each mainland NEM jurisdiction increased by 20-38\% between 2001 and 2012. During the same period, underlying energy demand increased by only $15 \%$.

Figure 6: $\quad$ Growth in summer peak demand

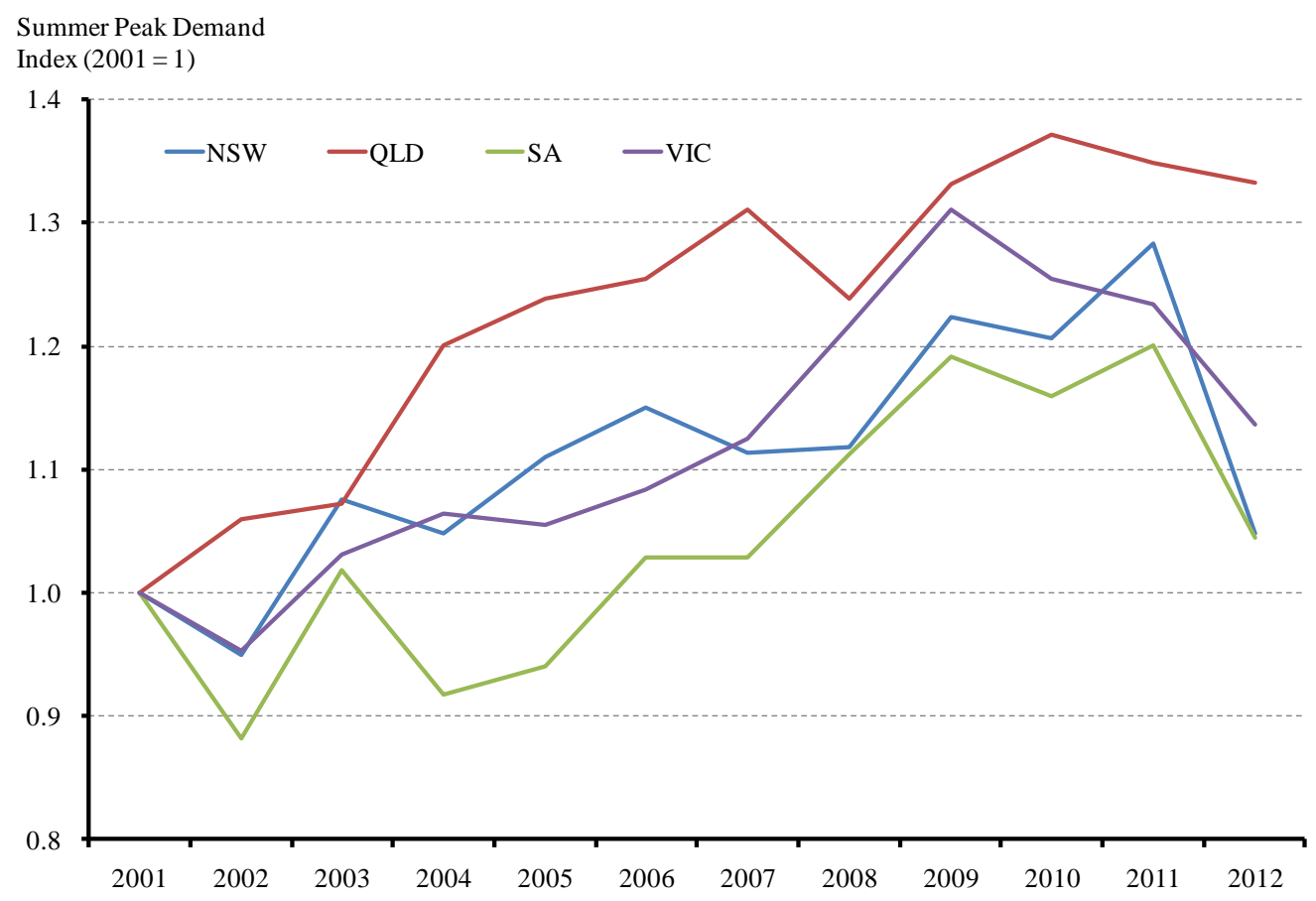

Source: AEMO, AGL Energy Ltd.

Energy demand growth rates have been moderating for several decades as Figure 7 notes. But most recently, an outright contraction in demand has occurred in Australia over the last two years (which appears in the 2010-2020 frequency distribution in Figure 7). This is a completely new phenomenon for the Australian electricity industry. At no time in Australia's history has electricity demand contracted, until now. This recent event finds its roots in the fallout from the global financial and economic crisis, the uncomfortably high Australian dollar and its adverse impacts on manufacturing loads, demand elasticity, energy efficiency and to a lesser extent, rising rooftop solar PV penetration. The most recent energy demand forecasts from the Australian Energy Market Operator expect modest growth between now and 2020 as Figure 7 implies. 
Figure 7: $\quad$ Electricity demand growth - frequency distributions

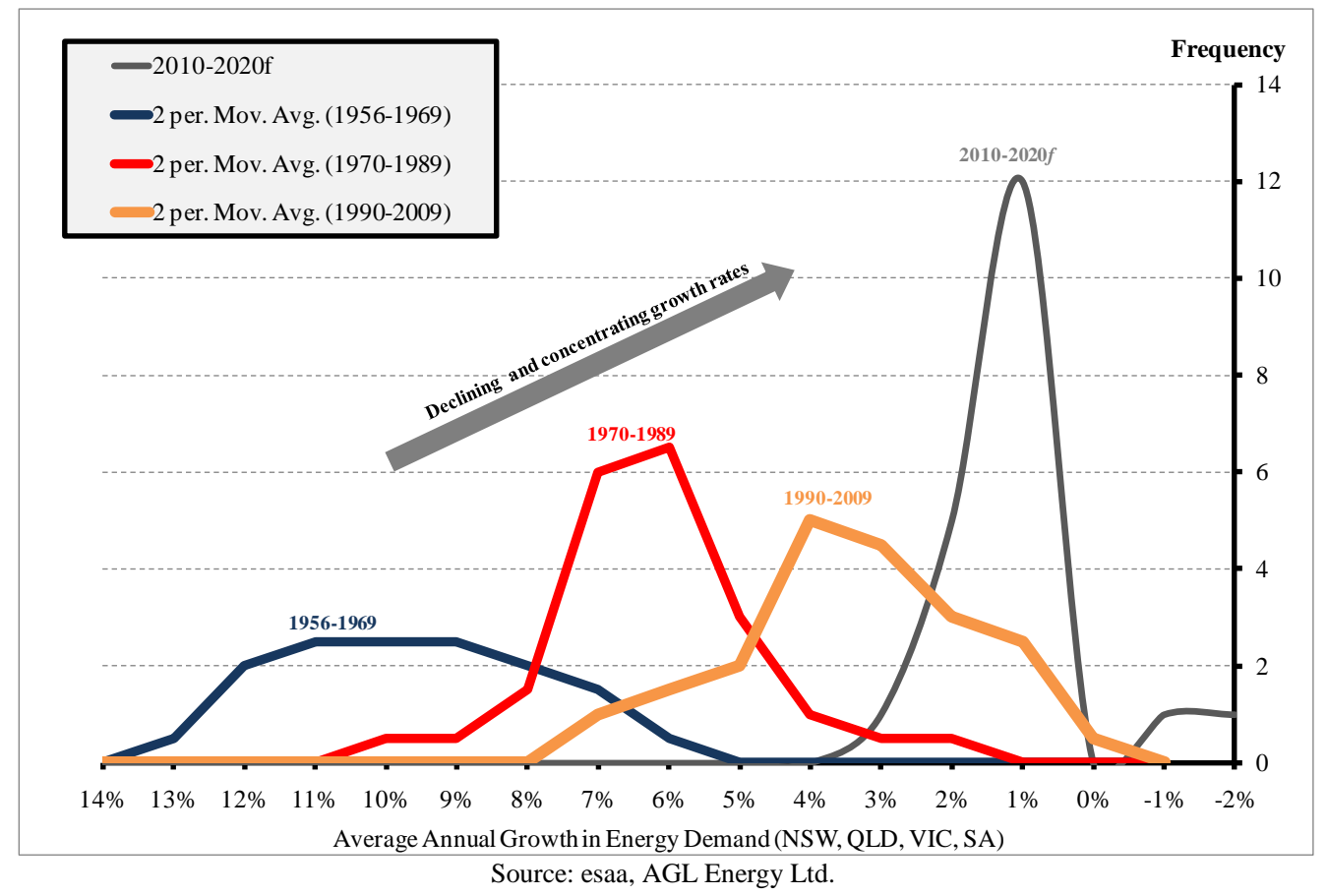

The decline in underlying energy demand (down 1\% nationally since 2010) has been used as evidence of network 'gold-plating'. Network operators build power systems to cope with peak demand due to the inability to store electricity through an inventory. Underlying or base electricity demand growth is not a prime driver of network investment. While it is true that peak demand and energy demand declined in all jurisdictions in the summer of 2012, such observations are generally made at the whole of system level. At the localised network element level, differential growth rates remain. Indeed, Energex in Southeast Queensland continue to forecast higher peak demand growth compared to underlying energy demand.

Policymakers must therefore focus on pricing structures and other incentives to reduce critical peak demand, not underlying energy demand. On the contrary, focusing only on underlying energy demand through efficiency schemes risks inducing a pricing spiral, whereby reductions in underlying energy demand but rises in critical peak demand result in poorer capacity utilisation, increasing costs and therefore prices, and in turn further energy demand reductions in an iterative process (Simshauser and Nelson, 2012).

Adverse effects of deteriorating capital utilisation are also starting to appear in generation plant performance statistics. In Figure 8, we reproduce Figure 3 but extend the data to 2011. Notice the rapid deceleration in the generation capacity utilisation rate. 
Figure 8:

Generation capacity utilisation in the NEM region $(1955-2011)$

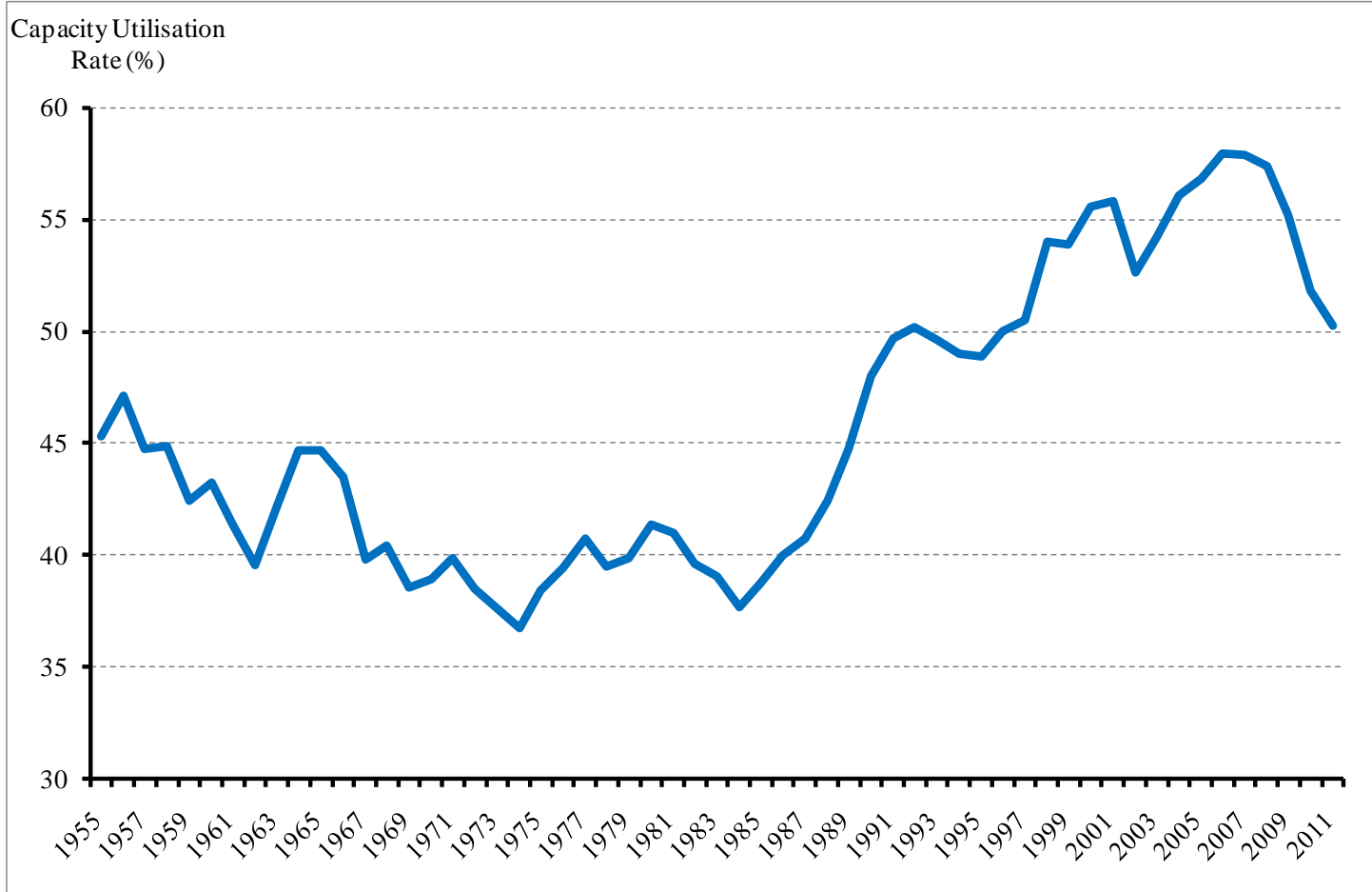

Source: esaa, AGL Energy Ltd.

Network operators have also had the task of increasing capital spending to meet the higher reliability standards in New South Wales and Queensland, and replace aging assets. However, the investment cycle presented in Figure 9 shows that the increase in capital spending is not without precedent.

Figure 9: $\quad$ The Electricity Investment 'Megacycle'

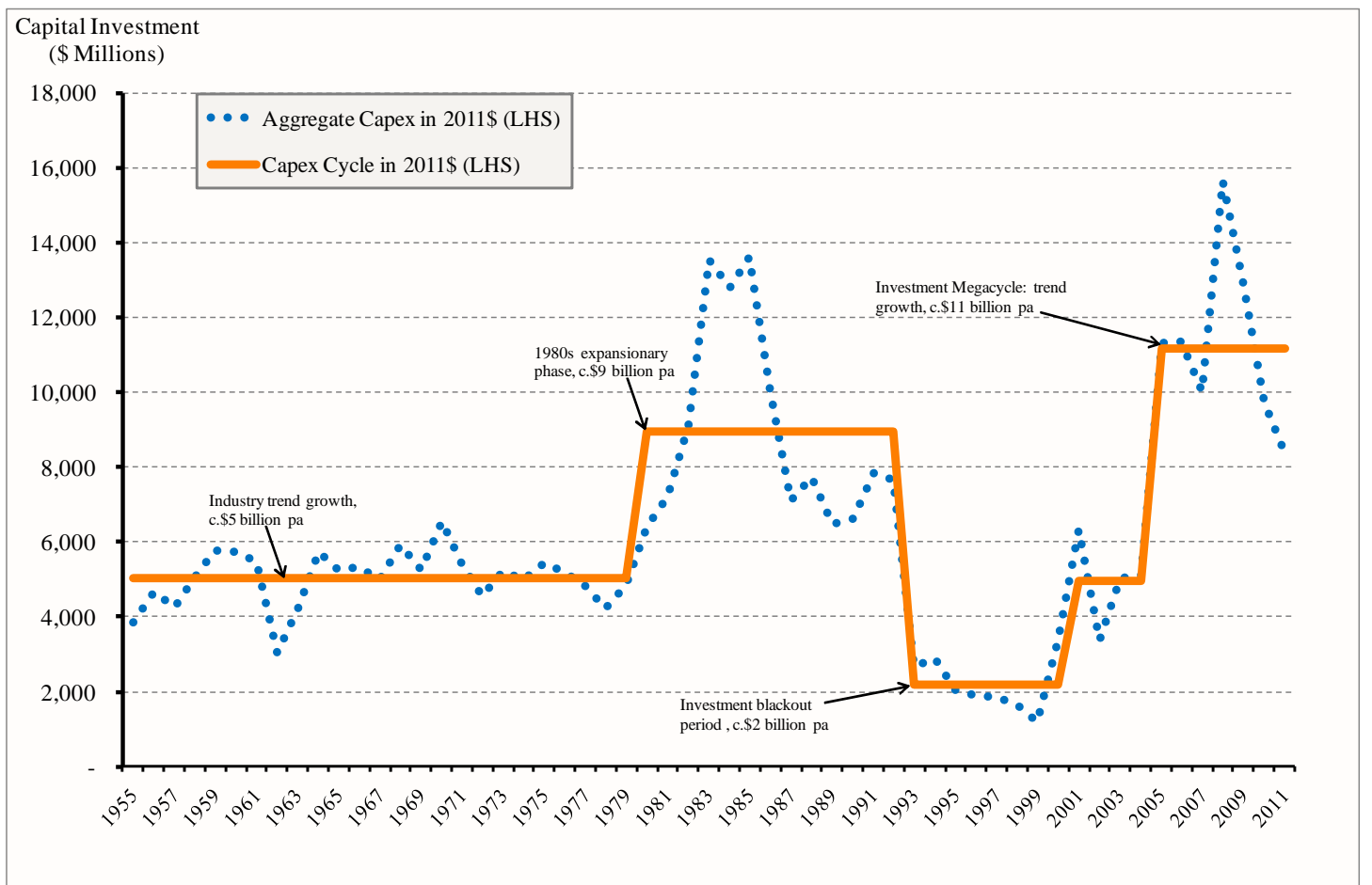

Source: Simshauser and Catt (2012) 
Figure 9 shows the investment cycle since 1955 across all fixed assets (i.e. generation, transmission and distribution). Investment from 1955-1978 was largely stable at about $\$ 5$ billion per annum, with demand growth throughout the (now) NEM jurisdictions averaging $7.9 \%$ per annum. In the next period spanning 1979-1990, demand growth slowed to 5.4\% but industry investment soared to about $\$ 9$ billion per annum. This coincided with a period of sharply rising residential demand (particularly peak winter residential demand) - residential demand increased by $16 \%$ over this period. The period from 1990-2000 was characterised by an investment blackout as excess capacity was utilised. From 2000-2005 investment returned to trend-levels. From the mid-2000s, the investment cycle was again kicked-off with capital in all industry segments to meet rapid increases in forecast peak summer demand and replace ageing assets as noted above.

\subsection{Wholesale Energy Costs}

There are two primary components of wholesale energy costs: capacity costs and fuel costs. Figure 10 shows the capital cost (that is, overnight capital cost) indices for open cycle gas turbines (OCGT or peaking power plant); combined cycle gas turbines (CCGT or base and semibase load gas power plants) and wind farms, along with the regional price of gas and coal.

Figure 10: $\quad$ Power Generation Capital Costs and Regional Fuel Costs

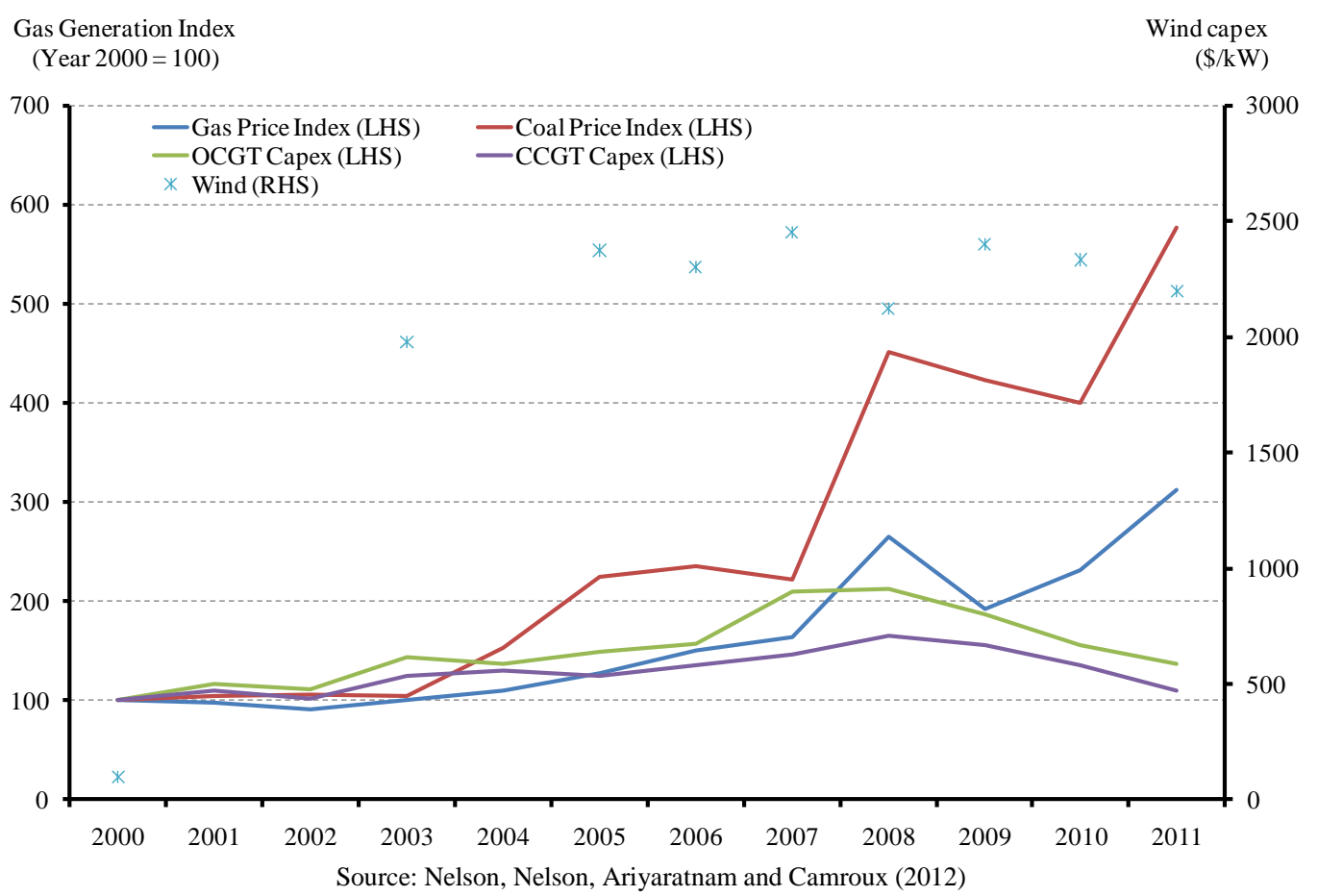

Figure 10 shows that in the period 2000-2007 (pre global financial crisis), the cost of building new power stations increased materially. This was due to both rising capital costs and costs of capital as Simshauser, Molyneux and Shepherd (2010) explain. However, it is fuel costs where the most material structural change is now occurring in the Australian electricity industry. Figure 10 demonstrates that for both coal and gas commodity costs, there has been significant and sustained upward pressure arising from globally synchronised pricing over the past decade - the origins of which can be traced back to 2003 and the structural changes occurring internationally (i.e. Chinese industrial growth). Historically, Australian power generators utilising black coal paid very low prices for thermal coal under long-dated domestic contracts. However, as a result of increasing export demand, and the fact that many incumbent generators are facing the end of their historic supply agreements, the price paid by many coal-fired generators in Australia may increase materially. And the price of gas is known to be rising due to Liquified Natural Gas 
(LNG) developments in Australia. This trend is in stark contrast to the United States, where the shale gas boom has resulted in sharply falling fuel costs.

Analysts often point to very low wholesale spot prices in the NEM as evidence that oversupply has resulted in cost reductions. However, this ignores the fact that investment in power generation cannot be banked on short-run dynamics, nor does all trade occur in the short-dated markets (Simshauser, 2010). Due to the long-lived nature of power generation investments, a Power Purchase Agreement (PPA), written by a counterparty with an investment-grade credit-rating has long been required prior to the development of any new capacity, be that thermal or renewable (Nelson and Simshauser, 2013). And so wholesale electricity costs are more complicated than short run prices - much the same way that the determination of mortgage interest rates are more complicated than the RBA cash rate. It is the long-run cost of generation supply which is important for considering longer-term retail electricity pricing trends.

The final driver of higher wholesale energy costs has been the carbon price. The fixed $\$ 23 /$ tonne carbon price introduced as part of the Clean Energy Future package has resulted in an increase in generation costs of about $\$ 21 / \mathrm{MWh}$. This is not unsurprising given that the Australian electricity market has an emissions intensity of around 0.9 tonnes per MWh ( 0.9 tonnes multiplied by the carbon price is $\$ 21 / \mathrm{MWh}){ }^{3}$

\subsection{Green Schemes}

There are three main types of renewable energy policies which have impacted electricity prices: (1) the Large-scale Renewable Energy Target (LRET); (2) the Small-scale Renewable Energy Scheme (SRES) which provides a fixed $\$ 40 / \mathrm{MWh}$ subsidy to installers of small scale solar PV systems; and (3) feed-in tariffs (FiTs) for solar PV systems at the State level.

LRET impacts on electricity prices have thus far been comparatively small given the output from utility-scale facilities. The impact on end-use electricity prices has been around $3.8 \%$ of the increases identified by AEMC (2011). The impact of LRET on NSW residential electricity bills is currently about $\$ 4.45 / \mathrm{MWh}$ of the c. $\$ 270 / \mathrm{MWh}$ headline price.

The combined impacts of solar PV feed-in tariffs and the SRES have also had a modest absolute impact on prices, although at a considerably higher unit cost given the relatively small output (due to lower capacity factors) from PV systems. In 2010 and 2011, premium Feed-in Tariffs led to a 100 fold increase in the installation of solar PV systems. This was primarily because installers benefited from being able to claim 15 years of output upon installation in the form of SRES payments - which were then subject to a further 'multiplier' of up to $5 \mathrm{x}$ at one point (i.e. the equivalent of 75 years of production in upfront subsidies). Unsurprisingly, when combined with premium Feed-in Tariffs, installation in some cases had an effective payback of less than three years as Nelson, Simshauser and Kelley (2011) and Nelson, Simshauser and Nelson (2012) explain. The result was a subsequent explosion in cumulative solar PV installed (although to be sure, this still represents a very small fraction of NEM installed capacity). This is shown in Figure 11. 
Figure 11: $\quad$ Small Scale Solar PV Cumulative Installed Capacity (2001-2011)

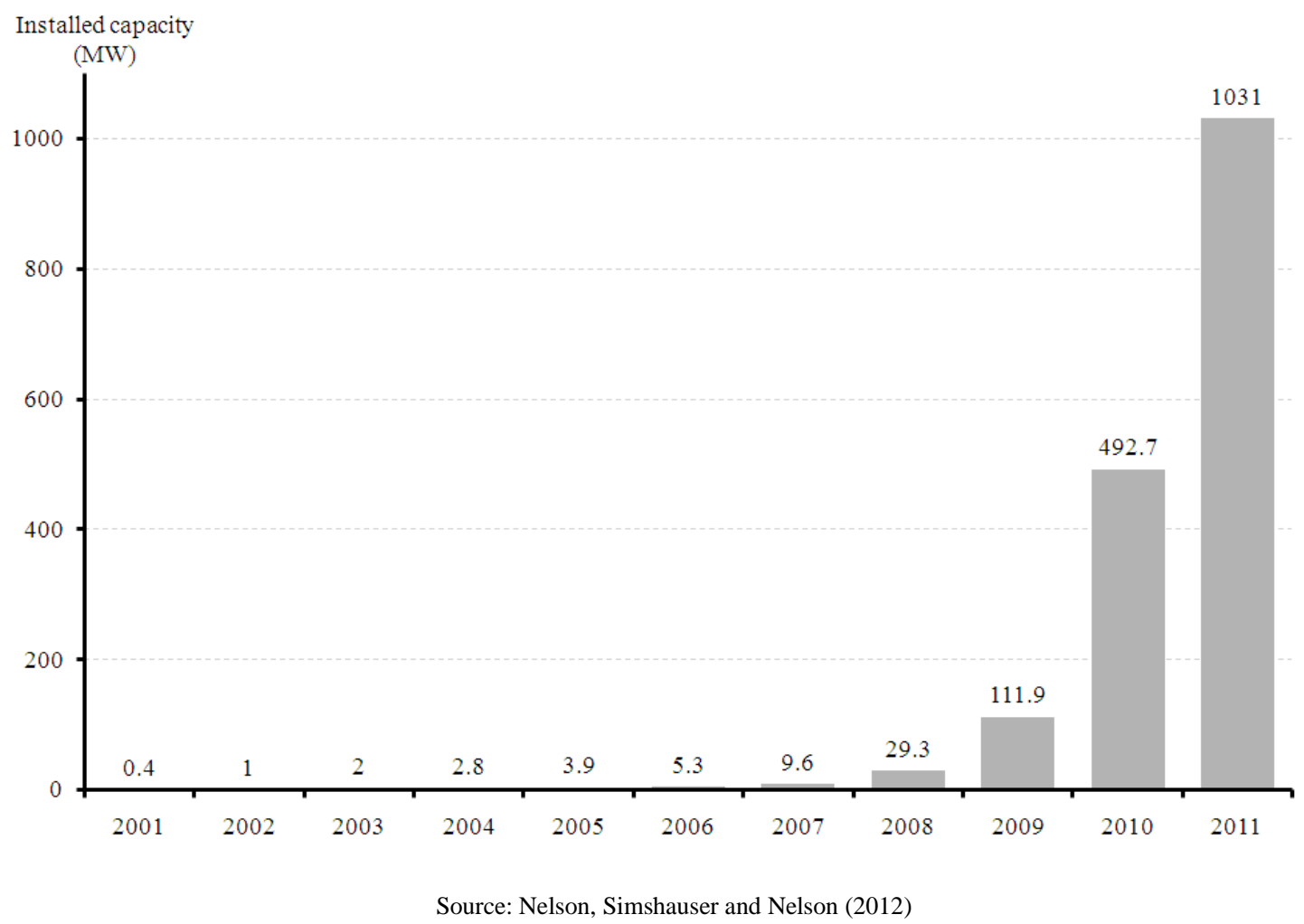

As a result of these discrete subsidies, the total costs of both schemes are being passed through to consumers. In 2012/13, the cost of SRES to NSW residential customers is estimated to be around \$6/MWh, and does not include the cost of the solar FiT scheme.

\section{Will prices continue to increase?}

There are, understandably, a variety of views in relation to whether electricity prices will continue to increase. In the very short-term, prices are likely to rise modestly as a result of the completion of the current investment cycle. However, our interest is in considering the longer-term and what prices might look like in 2020.

We have constructed a model of electricity tariffs in 2020 based upon potential changes in underlying costs relative to the 2012/13 Sydney default residential tariff, and we compare this with the 2007/08 tariff in Figure 12. 
Figure 12: $\quad$ Headline residential electricity tariff (Sydney)

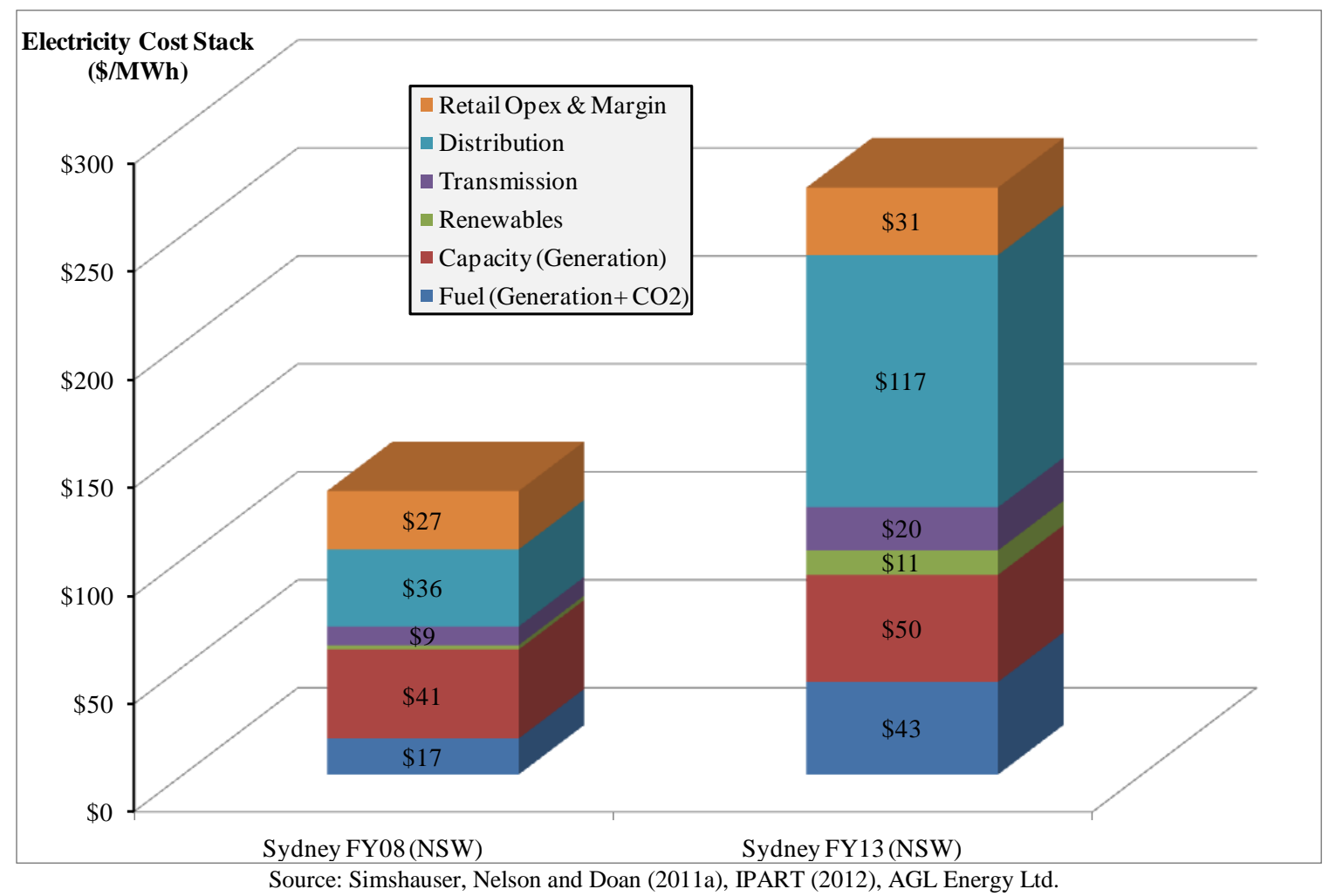

\subsection{Wholesale energy costs}

One of the most important projections to consider is the ratio of peak demand to underlying energy demand (i.e. power system load factor) to determine whether capacity utilisation is likely to improve or deteriorate. In its most recent projections, the Australian Energy Market Operator has revised down its projections of both underlying energy demand growth and peak demand growth due to changes in the broader economic outlook, reduced manufacturing due to the high currency, increased penetration of embedded solar PV and customer response to increased electricity pricing. Some energy market analysts are now arguing that because load growth is expected to moderate and excess capacity now exists, reforms aimed at peak load are no longer necessary. We believe this misses the point of demand-side reform, and more importantly, the predictable lags associated with microeconomic reforms. Power system load factors are at one of the lowest levels in recent memory. If load factors are to be substantially improved through peak load reductions, reforms need to occur well ahead of the envisaged requirement. There are two key reasons for this. First, a 'substantive' roll-out of interval meters, an unambiguous prerequisite to reform, will take at least 5-10 years in a competitive market place (as distinct from a mandated smart meter roll-out). Secondly, the industry itself will need to see sustained behavioural change during critical peak events as Simshauser and Downer (2012) explain.

For the purposes of our analysis through to 2020, we assume the most recent recommendations of the AEMC are adopted over the longer-term. That is, smart meters are not mandated, but rather, electricity metering becomes a contestable service. Additionally, customers would be able to choose whether to adopt a time-of-use tariff product, and we assume that most customers do Simshauser \& Downer (2012) demonstrated that more than $75 \%$ of customers would ultimately be better off with time-of-use pricing. Further, that the use of dynamic critical peak pricing, applied to the 12 most extreme weather events of the year, improves load factors by about 8 percentage points in line with the economic analysis contained in Simshauser \& Downer (2012). Under these conditions, consumers face cheap off-peak electricity rates, a more expensive peak rate, and on critical event days (i.e. extreme hot weather), a critical peak price. Most importantly, 
customers would not be compelled to pay for a smart meter or be placed on time-of-use tariffs. Rather, customers could choose to modify consumption in their own way. This is a critical distinction with the conventional model of mandating smart meters. It is important that consumers modify consumption to suit their own circumstances. It would be a poor public policy outcome if consumers suffered detrimental health impacts, for example, because of non-use of spatial heating and cooling. However, for many customers, a small adjustment to the thermostat of their airconditioning on peak summer demand days or turning off unnecessary household appliances at such times could result in substantial savings not only on their bill, but resource costs to society. As our modelling later reveals, this leads to material reductions in peak load electricity equipment, but more importantly, a greater utilisation of sunk assets.

Forecasting domestic well-head gas prices is critically important in determining future wholesale energy costs. As Australia moves toward exporting LNG on the east coast through the Gladstone LNG hub, it is likely that Australian east-coast gas markets will become at least partially connected to global markets for the first time (i.e. LNG contracts in Australia are linked to regional oil prices). Upward pressure on gas prices on the east coast market is already evident. Many industry analysts are forecasting well-head gas prices in the range of $\$ 6-\$ 9 / G J$. An outcome at the lower end of this range would be dependent on supportive public policy for further exploration and production of conventional and more importantly, non-conventional gas (i.e. Coal Seam Gas) to ensure sufficient supply for domestic and LNG loads. Without supportive public policy for additional exploration and production, prices could rise to the higher end of this range. Accordingly, we have modelled a second $\$ 9.00 / \mathrm{GJ}$ well-head gas price scenario to reflect such conditions.

The other critical element in considering future wholesale energy costs is the impact of carbon pricing. The Commonwealth Government has passed legislation which will effectively link Australia to the European Union Emissions Trading Scheme. Accordingly, the current 2020 forward price of EU Allowances (EUAs) is relevant in considering forward wholesale energy costs.

To provide an estimate of wholesale energy costs in 2020, we have utilised a half hour resolution partial equilibrium model of the NEM. Demand has been forecast to $2020 .^{4}$ Two scenarios based upon different gas and carbon pricing have been developed which are articulated in Table 1.

Table 1: New Entrant Scenarios and Modelled Wholesale Energy Costs ${ }^{5}$

\begin{tabular}{|c|c|c|c|c|}
\hline Scenario & $\begin{array}{l}\text { Gas Price } \\
\text { (CCGT) }\end{array}$ & Carbon Price & $\begin{array}{c}\text { Wholesale Energy } \\
\text { Cost }\end{array}$ & $\begin{array}{l}\text { Wholesale } \\
\text { Energy Cost } \\
\text { (8ppt Inc. in } \\
\text { Load Factor) }\end{array}$ \\
\hline Scenario 1 (Low) & $\$ 6.00 / \mathrm{GJ}$ & $\$ 0$ & \$74/MWh & $\$ 65 / \mathrm{MWh}$ \\
\hline Scenario 2 (High) & $\$ 9.00 / \mathrm{GJ}$ & $\$ 16.59 /$ tonne & \$103/MWh & \$93/MWh \\
\hline
\end{tabular}

\subsection{Networks}

While the most recent AEMO load forecasts suggest subdued load growth, this only provides information on aggregate demand at the whole of power system level. It is also important to examine load at the local network level. For example, we noted earlier that in Southeast Queensland, growth in peak demand is expected to continue at higher rates that underlying demand. Such effects are not likely to be isolated to Southeast Queensland. Thus is the importance of interval meters and time-of-use pricing in our analysis.

Interval meters and critical peak pricing, adopted by a large percentage of customers that would be likely to benefit, can be expected to result in material reductions in peak load growth over the 
long run. The utilisation of sunk transmission and distribution network assets can also be expected to improve along with avoided future augmentation costs at the network element level provided reforms are initiated well ahead of the next round of requisite expansion. Network operators in New South Wales have announced that near-term network tariff increases will be limited to general inflation rates. However, with load growth at $1.4 \%$ pa, improvements in load factors, and the possibility of privatisation from 2015 in New South Wales which will inevitably drive substantial productivity gains as Victoria's network businesses have aptly demonstrated, real price reductions are far more than a theoretical possibility. We have modelled these at just $1 \%$ per annum, although we expect the more likely scenario will be closer to 1.5 percentage points below the Consumer Price Index.

\subsection{LRET and SRES}

We assume that the SRES will cease to exist once the target of 4,000 GWh of annual small-scale renewable output is produced, and this is likely to occur well before $2020 .^{6}$ As a result, no SRES costs will apply in 2020. In relation to LRET, we have assumed the cost to be $\$ 8 / \mathrm{MWh}$ based the power system modelling analysis contained in Simshauser (2011).

\subsection{End user pricing forecast for 2020}

Given the above modelling results across the individual components of the supply chain, our projection of user tariffs in 2020 (2012\$) in Sydney is presented in Figure 13. This Figure shows that the end-user residential tariff between 1955 and 2013 (actual) and a projection for 2020 based upon the analysis in this paper. Real (line) and nominal (bar) prices are provided. For 2013 and 2020, we have also provided a breakdown of individual cost components. Based upon our assumption of improvements in capacity utilisation, all cost components decline in real terms with the exception of gas costs. By 2020 we project that real electricity prices may be $10 \%$ lower than in 2013. In our opinion, such a forecast provides policymakers with a clear direction in relation to future reform.

Figure 13: $\quad$ End user pricing forecast for 2020

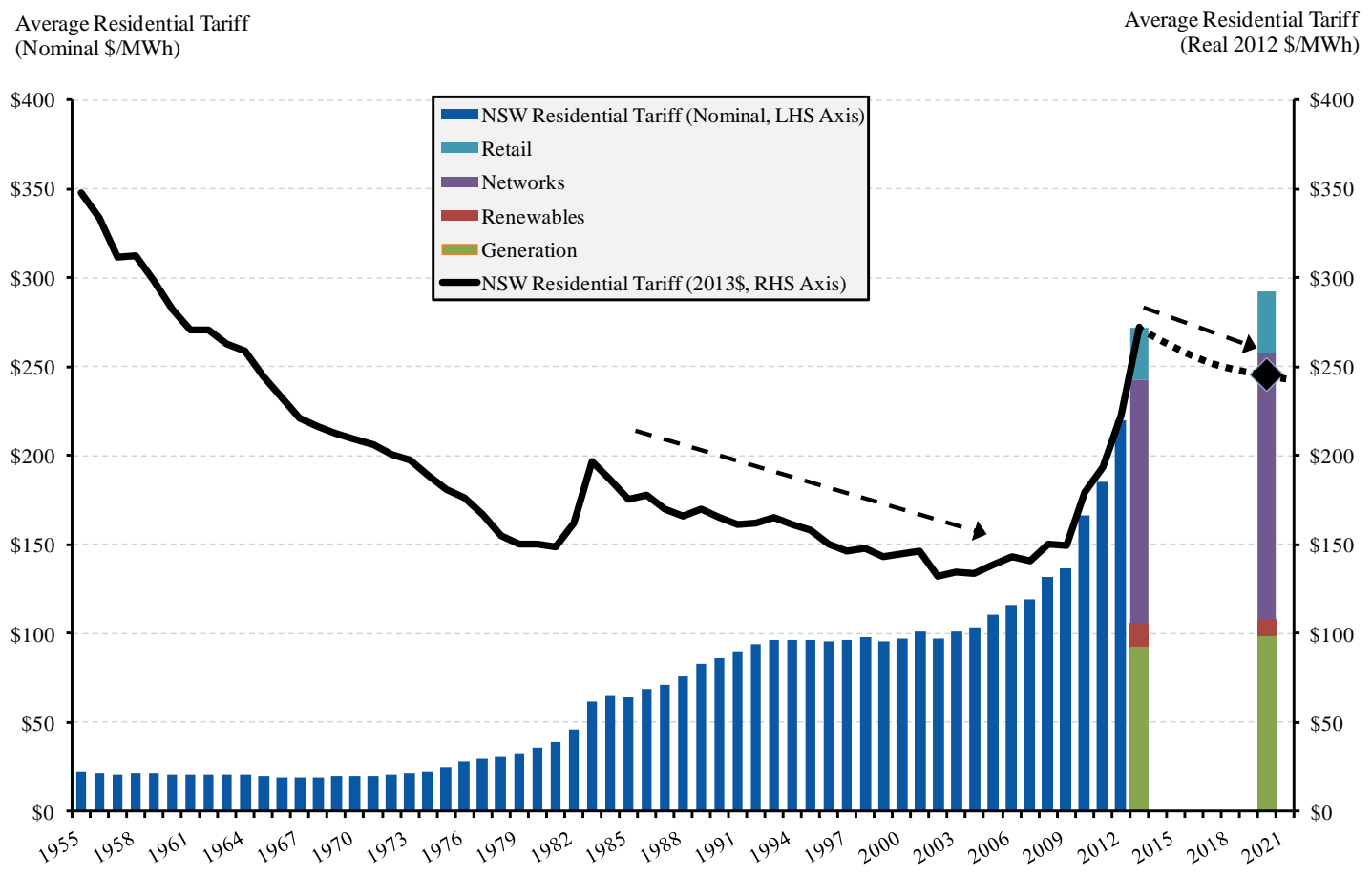




\section{A policy prescription for reform}

During 2012, economic regulators tasked with setting price caps (i.e. within competitive retail markets) in some States enforced price reductions on the competitive industry segment of generation/retail supply via regulatory instrument, and in the event, set price caps below industry long run costs. As energy economists, our advice to policymakers is that such developments are not helpful. In competitive markets, prices clear at the competitive level. The use of price regulation, and in particular, the use of highly imperfect information cannot drive real reductions in costs. At best, it is most unlikely to facilitate the competitive pressure required to drive innovation, which in turn will be quite essential for a competitive interval meter roll-out, and as noted earlier is an absolute prerequisite for dynamic pricing and the power system load factor improvements. Policies that will place downward pressure on future electricity prices are important, but applying regulatory instruments in the competitive segment is an especially blunt approach and is likely to have unintended consequences in our opinion. Deregulation of electricity prices, as implemented by Victoria and South Australia, is critical to achieving the price reduction forecasts in this paper.

Policymakers should note that while electricity prices have increased rapidly since 2008 , they declined in real terms for nearly two decades previously. This decline was driven by sustained microeconomic reforms of the supply-side. Absent further policy reform, real reductions in future electricity prices may fail to materialise to their fullest potential because one of the key drivers, investment to meet localised peak demand growth at the network element level, will persist - although quite clearly at more subdued rates than recent history as our Figure 7 implies. Our analysis and modelling projects a scenario whereby electricity prices fall in real terms through policy reform, competition and innovation. This is predicated on energy policy reforms in two key areas:

- $\quad$ A focus on increasing competition and facilitating choice to customers, rather than increasing regulation and in the event, reducing competition and stifling the innovation that follows. The removal of price controls and the introduction of time-of-use prices and in particular, critical peak pricing, is clearly important. Capacity utilisation is quite fundamental to understanding unit prices in industries with substantial fixed and sunk costs. Improving capital utilisation rates is unambiguously important for reducing electricity prices, even where transient excess capacity exists. Time-of-use pricing would promote innovation in the electricity sector and provide for greater economic productivity and efficiency for the nation.

- $\quad$ A focus on metering. Currently, in many jurisdictions metering charges are embedded in monopoly network prices. Metering costs need to be 'unpacked' and made a fully contestable service. Furthermore, where a new interval meter is deployed, chargeable exit fees for removing pre-existing meters needs to be capped by a depreciated, optimised, replacement valuation rather than arbitrary costs regardless of meter technology or age. It is important for metering reforms to be focused around customer choice. Mandated adoption of metering should be avoided. Instead, customers should not be forced to pay for a digital meter, and should be free to choose which tariff best suits their circumstances

Public policy certainty in relation to energy policy is also important. There is a wealth of economic literature on the costs of uncertainty in relation to energy policy ${ }^{7}$ due to the sector being the most capital-intensive in the world. It is important that politicians and policymakers consider the optimal long-term approach to power systems. As both the Federal Energy Minister and Shadow Energy Minister have stated to the authors, the energy industry and its policy settings are simply too important to be politicised, because the long run costs of doing so are so great to our nation. 
The most recent energy demand forecasts make for sobering reading to the energy industry. But this is not a reason to stall demand-side reform. The sheer lag that can be expected with the widespread adoption of interval meters under a competitive (non-mandated) rollout cannot be underestimated. Similarly, load factor improvements need to be demonstrable over multiple reporting periods. Considered in this light, demand-side reform is not an event, but a sustained 10 -year plus exercise. To be sure, any delays to demand-side reform will not result in imminent disaster and it would be disingenuous of us to suggest otherwise. Conversely, when a patient is sick, the sooner medicine is prescribed, the sooner they recover.

Our recommendations are predicated on an underlying philosophy of customer choice and economic efficiency. To increase power system productivity, the prerequisites are incentives, capability and flexibility as Banks (2012) notes. Competition drives innovation, so if regulation that has the effect of reducing competition, innovation will be reduced and it follows that productivity will not be enhanced. Similarly, from a capability perspective, Banks (2012) highlights the importance of cost reflective pricing and therefore any regulation that prevents this capability will also harm productivity. And finally, as Banks (2012) also notes, there is no silver bullet when it comes to enhancing productivity - all leavers must be pulled. In all instances (i.e. incentives, capability and flexibility), price regulation is sending an inconsistent message about what is important in terms of Australia's power system productivity.

Real reductions in electricity prices achieved between 1985 and 2008 occurred because of substantial supply-side reforms to the electricity industry. The drivers of higher costs between 2008 and 2012 coincide with a period where reform efforts stalled. Australia has an opportunity to embrace the 'missing reforms'. 2013 represents a significant opportunity for governments, policymakers, regulators, the electricity industry, consumers, investors and the community to agree on appropriate demand-side reforms that deliver benefits to all Australian electricity consumers.

\section{References}

Australian Energy Market Commission (2011), Retail electricity price estimates - Final Report for 201011 to 2013-14, AEMC Publication, Sydney.

Banks, G. (2012), Productivity Policies: the to-do list, Productivity Commission, Canberra.

esaa: Energy Supply Association of Australia, (2012), Electricity Gas Australia, esaa publication, Melbourne.

Faruqui, A. (2010), "Residential dynamic pricing and energy stamps", Regulation, Winter 2010-2011, pp 45.

IPART, (2011), "Changes in regulated electricity retail prices from 1 July 2011”, IPART Publication, Final Report June 2011, Sydney. Available at http://www.ipart.nsw.gov.au

NCC: National Competition Council, (2003), “2003 NCP assessment”, National Competition Council Publication, Melbourne. Available at http://ncp.ncc.gov.au/docs/2003\%20assessment.pdf

Nelson, J. and Simshauser, P. (2013), “Is the Merchant Power Producer a Broken Model?", Journal of Energy Policy,53( Feb): 298-310.

Nelson, T., Kelley, S., Orton, F. and Simshauser, P. (2010), "Delayed carbon policy certainty and electricity prices in Australia", Economic Papers, 29(4): 446-465. 
Nelson, T., Nelson, J., Ariyaratnam, J. and Camroux, S. (2012), “An analysis of Australia's Large Scale Renewable Energy Target: restoring market confidence", AGL Applied Economic Research Working Paper No.35, Available at: http://www.aglblog.com.au/wp-content/uploads/2012/09/No-35-LRET-FINAL.pdf.

Nelson, T., Simshauser, P. and Nelson, J. (2012), " Queensland Solar Feed-In Tariffs and the Merit-Order Effect: Economic Benefit, or Regressive Taxation and Wealth Transfers?", Economic Analysis and Policy, 42(3): 277-301.

Parer, W. (2002), "Towards a truly national and efficient energy market", Council of Australian Governments Energy Market Review, Commonwealth of Australia, Canberra. Available at http://www.ret.gov.au/Documents/mce/_documents/FinalReport20December200220050602124631.pdf

Simshauser, P. (2010), "Vertical integration, credit ratings and retail price settings in energy-only markets: navigating the Resource Adequacy problem", Journal of Energy Policy, 38(11): 7427-7441.

Simshauser, P. (2011), "The hidden cost of wind in a thermal power system: what cost?", Australian Economic Review, 44(3): 269-292.

Simshauser, P. and Catt, A. (2012), "Dividend policy, energy utilities and the investment megacycle", The Electricity Journal, 25(3):4, 63-87.

Simshauser, P. and Downer, D. (2012), "Dynamic pricing and the peak electricity load problem", Australian Economic Review, 45(3): 305-324.

Simshauser, P., Molyneux, E. and Shepherd, M. (2010), "The entry cost shock and the re-rating of power prices in NSW, Australia", Australian Economic Review, 43(2): 114-135.

Simshauser, P. and Nelson, T. (2012), "The second-round effects of carbon taxes on power project finance”, Journal of Financial Economic Policy, 4(2): 104-127.

Simshauser, P. and Nelson, T. (2012), "The Energy Market Death Spiral - Rethinking Customer Hardship", AGL Applied Economic Policy and Research Working Paper No.31, Sydney. Available at: http://www.aglblog.com.au/wp-content/uploads/2012/07/No-31-Death-Spiral1.pdf

Simshauser, Nelson and Doan, (2011a), "The Boomerang Paradox Part 1: how a nation's wealth is creating fuel poverty", The Electricity Journal, 24(1): 72-91.

Simshauser, Nelson and Doan, (2011b), "The Boomerang Paradox Part 1: how a nation's wealth is creating fuel poverty", The Electricity Journal, 24(2): 63-75. 


\section{Appendix I: AMEC Forecast of Electricity Prices to 2013/14}

Tariff

(\$/MWh)

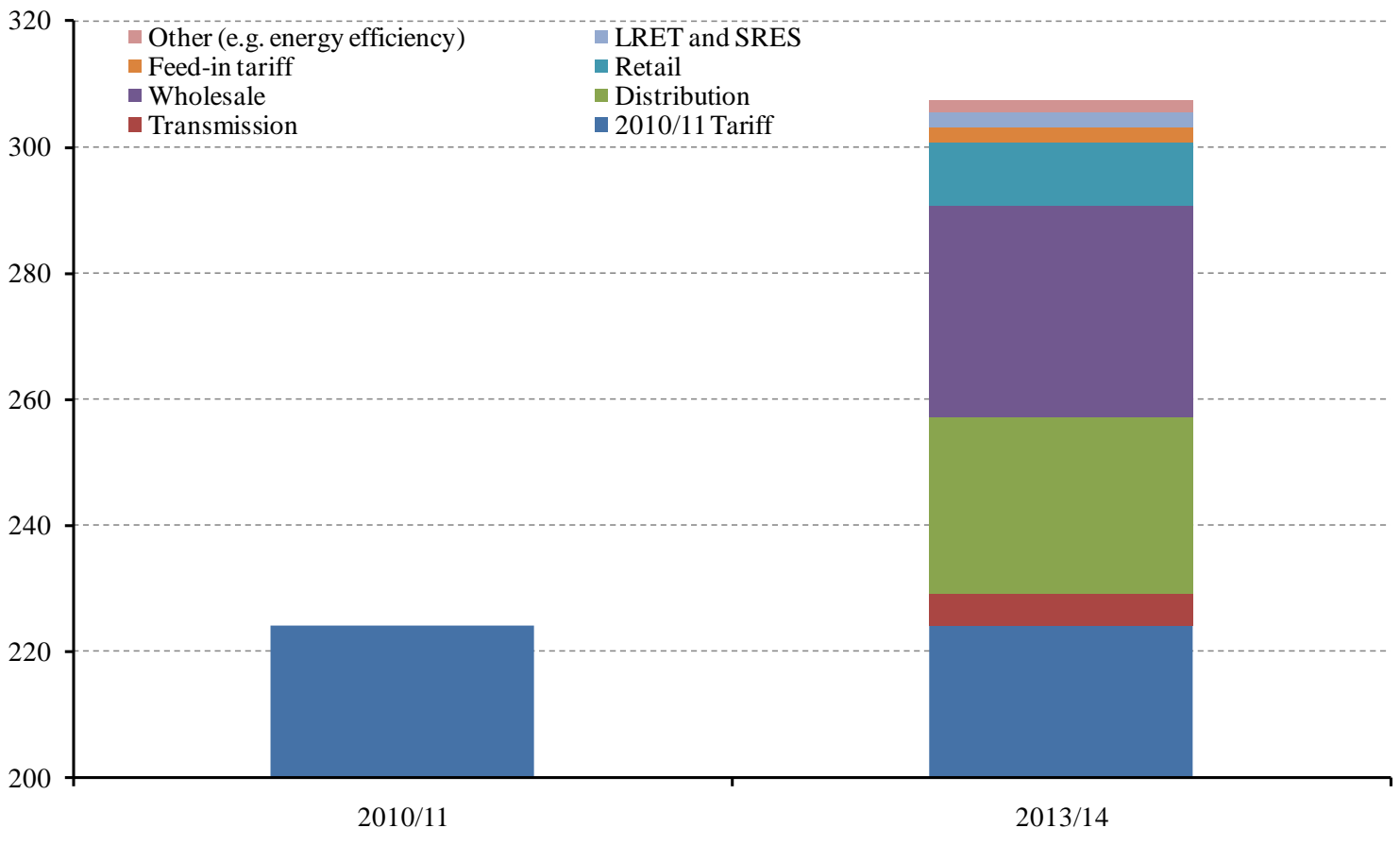

Source: AEMC (2011)

${ }^{1}$ The AEMC initiated their Power of Choice review in early 2011.

${ }^{2}$ Even these 'ripple control loads' are falling due to solar and gas hot water systems - while clearly helpful on environmental grounds, a side-effect is that it further reduces power system productivity levels.

${ }^{3}$ For further information see AEMO analysis of the introduction of the carbon price. Available at: http://aemo.com.au/News-and-

Events/News/AEMO-Releases-NEM-Carbon-Price-Analysis. Accessed on 28 November 2012.

${ }^{4}$ Demand has been forecast using the same methodology in Nelson, Kelley, Orton and Simshauser (2010).

${ }^{5}$ We have assumed no change in overnight capital costs of generation plant or the cost of capital but adjusted costs downward by $20 \%$ based upon potential depreciation of the \$AUD by 2020. We also include a small allowance for gas pipeline costs to the well-head in the capital cost.

${ }^{6} \mathrm{See}$ http://aemo.com.au/Electricity/Planning/Forecasting/National-Electricity-Forecasting-Report-2012 for further information.

Accessed online on 28 November 2012.

${ }^{7}$ There is a rich and detailed existing economic literature related to the costs of policy uncertainty in Australia's electricity markets. See for example Nelson, Simshauser, Orton and Kelley (2012a), "Delayed carbon policy certainty and electricity prices in Australia: A concise summary of subsequent research", Economic Papers, Vol. 31, No.1, pp.132-135; Frontier Economics (2010), "What is the Cost of Carbon Uncertainty", Frontier Economics Bulletin, Frontier Economics, Melbourne; and Simshauser and Nelson (2012a). 